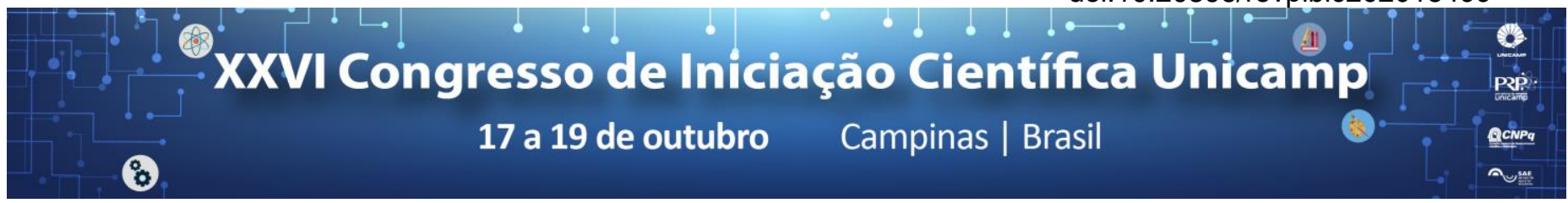

\title{
Perfil profissional dos Egressos da Faculdade de Odontologia de Piracicaba
}

\section{Gabriel W.Silva*, Fabio Luiz Mialhe}

\section{Resumo}

A caracterização do perfil profissional e socioeconomico do egresso de uma Faculdade de Odontologia, como a FOP/Unicamp, traz inúmeros indicativos de caráter construtivo e reflexivo sobre o tipo de formação oferecida por uma faculdade e, além disso, como essa formação e experiencias clínicas durante a graduação podem influenciar no tipo de profissional que entra no mercado de trabalho ou no próprio meio acadêmico. Este estudo apresenta os seguintes objetivos: 1. Identificar quais são as principais atividades desenvolvidas pelos egressos, após o término da graduação na FOP/Unicamp, analisando o perfil socioeconomico associado ao tipo de carreira escolhida 2. Buscar verificar qual o tempo de dedivação à profissão tendo em vista a sustentabilidade como profissional no mercado de trabalho 3 . Verificar renda aferida e a satisfação profissonal do egresso.

Palavras-chave:

Perfil, profissional, odontologia.

\section{Introdução}

O Sucesso profissional na área da odontologia não deve ser consderado como consequência apenas de suas habilidades técnicas para realizar procedimentos clínicos. É resultado da conjuntura de fatores sociais e psicológicos ,como também de sua formação acadêmica que exercêm influencia considerável sobre o seu comportamento e interações com seus pacientes. São justamente essas interações que corrroboram para o sucesso e a satisfação profissional do cirurgião-dentista.

Neste sentido é necessário que se tenha uma avaliação atual da situação do perfil profissional dos egressos segundo a realidade do país e as demandas da população, a fim de se ajustar a prática profissional e a formação dos recursos humanos ao mundo "real".

A Universidade Estadual de Campinas através da sua Faculdade de Odontologia, tem demonstrado bastante destaque na formação profíssional do cirurgião-dentista e foi a referência para o desenvolvimento desta pesquisa.

\section{Resultados e Discussão}

Amostra: 95 ex-alunos que concluíram o curso de graduação entre os anos de 2010 a 2016 na FOP/Unicamp.

Instrumento de coleta dos dados: questionário online.

Coleta dos dados: $O$ questionário foi enviado aos emails do banco de dados da Coordenadoria de Graduação da Faculdade de Odontologia de Piracicaba e aos perfis desses ex-alunos presentes em uma rede social (Facebook).

Análise dos dados: realizada descritivamente por meio de gráficos de distribuição de frequência.
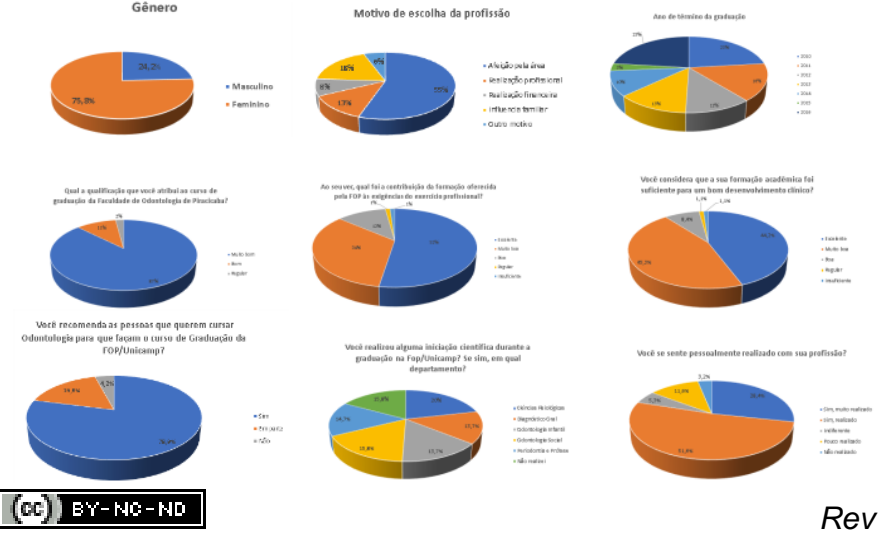

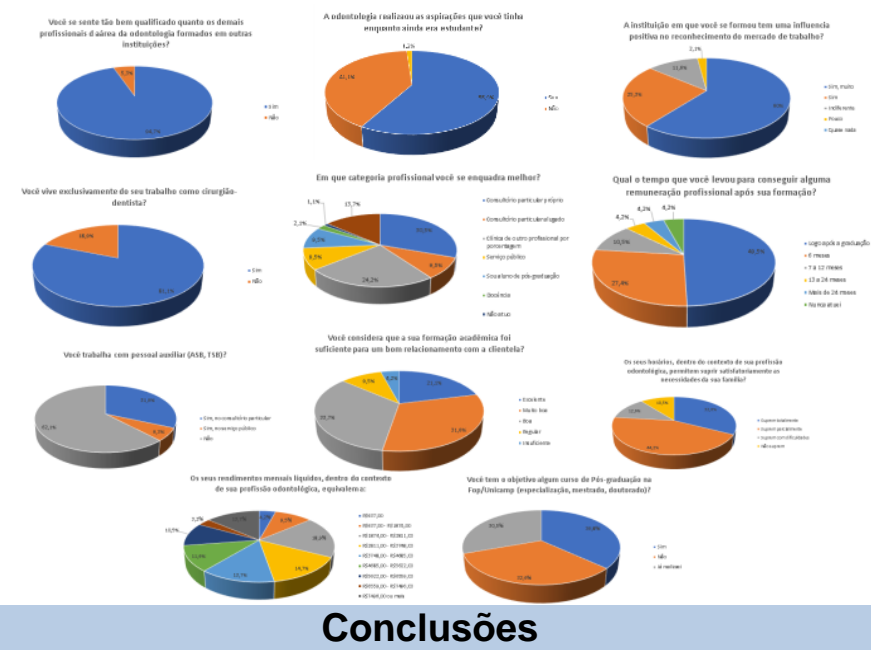

A análise da amostra avaliada evidenciou que os profissionais formados na FOP/Unicamp saem desta instituição com capacidades técnicas, clínicas e acadêmicas que repercutem de forma bastante positiva na sua atuação no mercado de trabalho. Entretanto, existem algumas ressalvas, pontos que poderiam ser melhorados para contribuir ainda mais para a formação final do cirurgião-dentista formado nesta instituição e que devem ser considerados pela Instituição.

\section{Agradecimentos}

Pela colaboração e pelo apoio que recebi durante o fomento desta pesquisa, apresento à Faculdade de Odontologia de Piracicaba, à Universidade Estatual de Campinas, à Pró-reitoria de Pesquisa da Unicamp, ao Programa Institucional de Bolsas de Iniciação Científica e ao Serviço de Apoio ao Estudante os meus sinceros agradecimentos.

\footnotetext{
${ }^{1}$ BARTLETT, L.H.; ERVIN, S.A.; GUO, I.Y. Text Dent J 1997; 114 (5): 19-22. ${ }^{2}$ Bastos, J.R.M, Aquiline, A.G.; Almeida, B.S.; Lauris, J.R.P.; Bijella, V.T.V. J. appl. oral sci 2003;11(4):283-9.

${ }^{3}$ CROSATO, E.M.; CALVIELLI, I.T.P; BIAZEVIC, M.G.H.; CROSATO, E. RPG rev. posgrad; 10(3):217-26, jul.-set. 2003.

${ }^{4}$ GUSHI, L.L.; WADA, R.S.; SOUZA, M.L.R. . Rev. Assoc. Paul. Cir .Dent 2004; 58(1):19-23.
} 